\title{
ADEQUAÇÃO DE PLATAFORMAS DE ALUMÍNIO PARA TRABALHO EM ALTURA*
}

\author{
Willy Ank de Morais ${ }^{1}$ \\ Luiz Claudio Ramos Lima ${ }^{2}$ \\ Heretiano Dalmacio Sampaio Junior ${ }^{3}$ \\ Marcio de Morais Tavares ${ }^{4}$
}

\begin{abstract}
Resumo
A Norma Regulamentadora 18 (NR 18) requisita que o trabalho em telhados e coberturas devem ser efetuados com uso de dispositivos dimensionados por profissional legalmente habilitado e que permitam a movimentação segura dos trabalhadores. A forma tradicionalmente mais segura de locomoção em telhados e coberturas é através de passarelas, que devem ser adequadamente fixadas à estrutura destes. Neste trabalho foram dimensionados e fabricados componentes de alumínio para a fixação mecânica de plataformas-escadas em alumínio. Estes componentes foram adequadamente soldados às plataformas de forma a obter um produto final mais seguro e adequado às operações de manutenção de telhados, especialmente em galpões metálicos de grandes proporções, como foi o caso dos galpões onde este produto foi empregado pela primeira vez.
\end{abstract}

Palavras-chave: Alumínio; Elementos Finitos; soldagem TIG; GTAW.

\section{ADEQUACY OF ALUMINIUM PLATFORMS FOR WORK AT HEIGHTS}

\begin{abstract}
The Brazilian Regulatory Standard 18 (NR 18) requests that the manual work on roofs must be made with the use of devices sized by legally qualified professionals to allow safe movement of workers. The safer form of locomotion during working on roofs are traditionally obtained by the use of walkways or platforms, which must be properly fixed to the roofing structure. In this work, it were dimensioned and fabricated aluminum components for mechanical fixing of aluminum. These components have been properly welded to the platforms ladder to obtain a safer final product as well suitable for roofing maintenance, especially in metal sheds of major proportions, as was the case of the warehouses where the product was first used.
\end{abstract}

Keywords: Aluminium; FEA; Pulsed GTAW.

1 Doutorando, Mestre, Engenheiro e Técnico em Metalurgia e Materiais, Sócio-Diretor da Willy Ank Soluções Metal-Mecânicas, Professor Mestre da UNAERP-Guarujá e Professor Adjunto da Universidade Santa Cecília (UNISANTA), Santos, SP, Brasil (wmorais@unaerp.br).

2 Engenheiro Mecânico pela UNISANTA, representante regional da VirtualCAE e Consultor em Engenharia da INSPEBRAS, Praia Grande, SP, Brasil (luiz@inspebras.com.br).

3 Engenheiro Industrial Mecânico e graduando em Direito na UNISANTA, Diretor Administrativo, INSPEBRAS, Praia Grande, SP, Brasil (heretianojr@inspebras.com.br).

4 Engenheiro Químico, Mestre em Engenharia Mecânica, Doutorando em Engenharia Química, Coord. do Curso de Eng. Civil e de pós graduação em Eng. de Segurança do Trabalho da UNAERP, Guarujá, SP, Brasil (mtavares@unaerp.br). 


\section{INTRODUÇÃO}

A finalização e manutenção de coberturas de galpões tem sido feita de várias formas, muitas delas consideradas inseguras ou mesmo perigosa aos trabalhadores envolvidos [1]. Para evitar este tipo de situação, a norma NR-18 [2] do Ministério do Trabalho e Emprego requisita, entre outras condições, que:

18.18 Telhados e Coberturas:

18.18.1 Para trabalho em telhados e coberturas devem ser utilizados dispositivos dimensionados por profissional legalmente habilitado e que permitam a movimentação segura dos trabalhadores. [2]

A forma mais segura dos trabalhadores se locomoverem em telhados e coberturas é através de passarelas para telhado [1], que podem ser empregadas para telhados do tipo plano inclinado com uma ou duas águas ou telhado "Shed" (com alpendre):

Estas plataformas são geralmente fabricadas em duralumínio antiderrapante [3 e 4] e substituem com vantagens as suas equivalentes feitas em madeira, possibilita melhor distribuição da carga do que as tábuas que tendem a ficar instáveis quando pisadas nas bordas. Tipicamente cada unidade tem um comprimento de $2,5 \mathrm{~m}$, largura de 40 a $45 \mathrm{~cm}$, peso de $13 \mathrm{~kg}$ (sem degraus) ou $15 \mathrm{~kg}$ (com degraus). A Figura 1 ilustra $o$ aspecto e operação com estas plataformas.
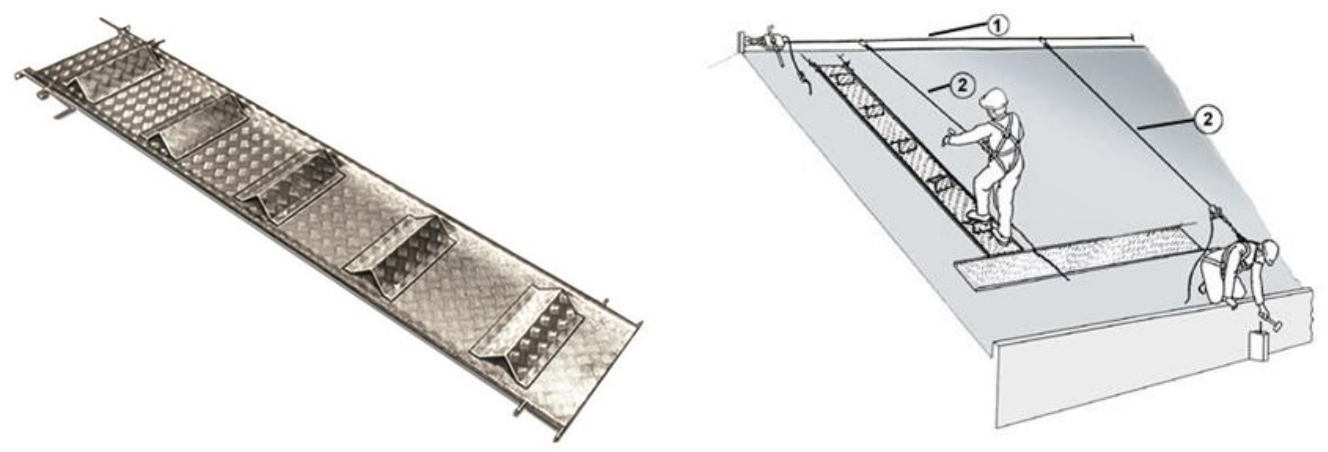

Figura 1. llustração de plataformas empregadas na construção ou manutenção de telhados [4].

As passarelas possuem a superfície de contato com o telhado lixada para melhor aderência. Dependendo da inclinação do telhado e/ou telhas com superfícies úmidas e escorregadias é recomendável utilizar correntes galvanizadas com elos de $3 \mathrm{~mm}$ de diâmetro fixadas na cumeeira e conectadas por mosquetões aos olhais existentes nas passarelas, conforme Figura 2. 


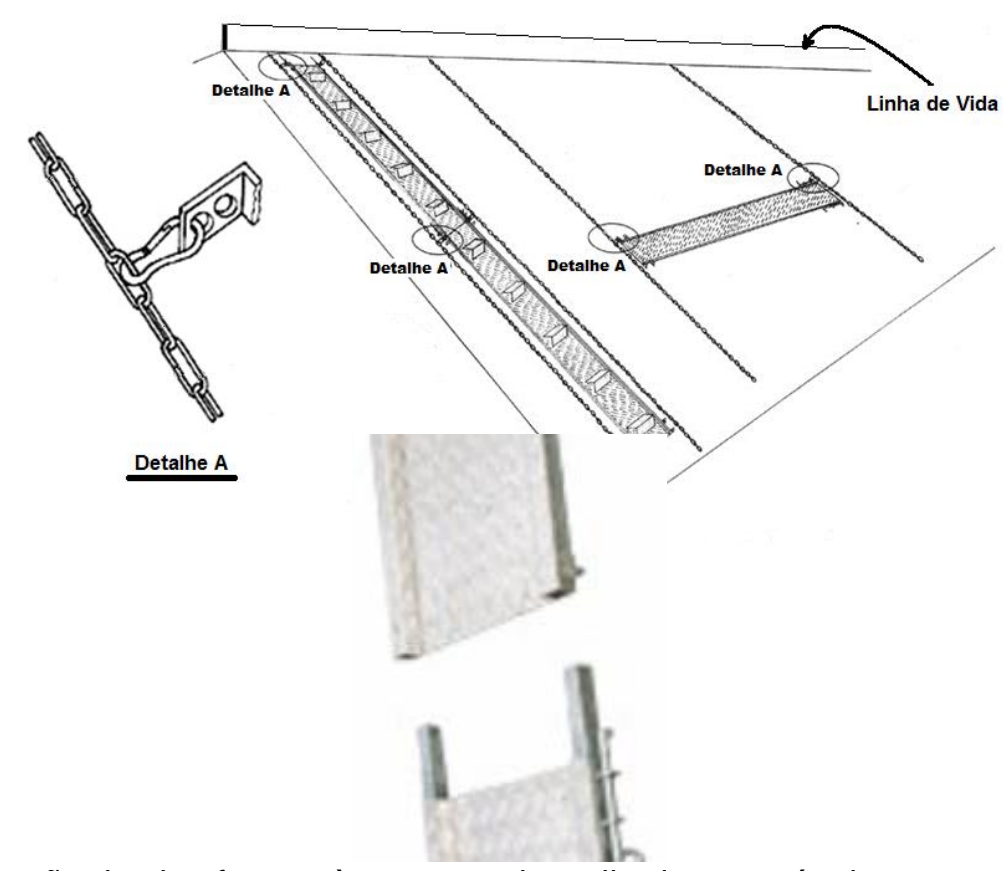

Figura 2. Fixação de plataformas à estrutura dos telhados através de mosquetões e olhais.

$\mathrm{Na}$ manutenção de telhados e coberturas, as passarelas de telhado são colocadas diretamente sobre as telhas e unidas, sem auxílio de ferramentas, por ferrolhos com trava de segurança. Podem, também, serem empregadas no sentido transversal das telhas (montada sempre próxima às terças). Em locais com inclinação superior a 25 graus obrigatório que estas tenham degraus [2, 3 e 4]. Com estas plataformas é possível movimentar-se até a 50 graus de inclinação [4].

As plataformas também são empregadas na instalação de telhados em coberturas novas. Neste caso, estes equipamentos podem ser fixados através de cabos de aço ou de 'arranques' metálicos que ficam mecanicamente travados aos elementos estruturais da cobertura do telhado (terças). Os 'arranques' atuam como elementos de fixação segura das plataformas à estrutura da cobertura em fabricação.

O presente trabalho foi desenvolvido para adaptar plataformas de alumínio para uma fixação mais simples, rápida e segura a estruturas de telhados. Esta adaptação emprega dispositivos de fixação, também constituídos de alumínio, que foram desenhados e dimensionados para se ajustar corretamente aos componentes da estrutura do telhado nos quais se apoia a telha (também conhecidos como 'terças'). A fabricação do produto final, adaptado, foi feita no Centro de Soldagem da INSPE///BRAS ${ }^{\circledR}$.

\section{MATERIAIS E MÉTODOS}

As plataformas empregadas no trabalho são de fabricação nacional, constituídas por chapas de alumínio genericamente descritas pelo fabricante das plataformas como sendo duralumínio [3 e 4]. Na realidade estas são constituídas de chapas de alumínio gravadas em alto relevo com um padrão antiderrapante e obtidas a partir de ligas de alumínio da série 3XXX (Al-Mn, AA3105). A espessura das chapas é de $2,00 \mathrm{~mm}$ e sua condição de fornecimento é com encruamento $1 / 2$ duro $(\mathrm{H} 14)$. A composição química e características de tração destas plataformas está descrita na Tabela 1.

As plataformas são obtidas pela união de unidades que possuem um comprimento de $2,5 \mathrm{~m}$; largura de 40 a $45 \mathrm{~cm}$ e peso de $13 \mathrm{~kg}$ (sem degraus) ou $15 \mathrm{~kg}$ (com degraus). Como o foco do trabalho é dar mais segurança a plataformas empregadas 
em maiores ângulos de inclinação, foram utilizadas unidades que contém degraus, conforme ilustrado na Figura 1, assim apresentando um peso por unidade de $15 \mathrm{~kg}$.

Para fazer a proposta inicial do tipo de dispositivo ou acessório para fixação mecânica destas plataformas à estrutura do telhado, considerou-se que os componentes seriam fabricados em alumínio comercialmente puro da série $1 \mathrm{XXX}$ (AA1060), cuja composição e características obtidas em tração também estão mostradas na Tabela 1, na condição recozido (O). Neste caso, esta condição oferece conservadorismo ao cálculo estrutural e também permite empregar qualquer tipo de liga ou condição de fornecimento para fabricar estes componentes em alumínio, desde que a liga escolhida permita sem emprego como previsto. Além disso, a geometria dos componentes de fixação foi concebida de forma a impactar ao mínimo o possível na massa total da plataforma e fornecer, ao mesmo tempo, uma fixação segura destas plataformas aos elementos estruturais do telhado.

Após o dimensionamento do componente, da definição de sua geometria e da verificação de sua adequabilidade às condições de segurança, foram obtidas chapas de alumínio comercial para executar o projeto. Para a execução mais precisa do dimensionamento, via Método de Elementos Finitos (FEA) e assim oferecer um memorial de cálculo mais detalhado, amostras do material adquirido foram testadas em tração, à temperatura ambiente, empregando-se uma máquina universal de ensaios mecânicos EMIC modelo DL10000. Os ensaios foram realizados em Corpos de Prova de tração planos conforme NBR ISSO 6892 [7].

Com os dados obtidos diretamente do ensaio de tração, foi realizado um refinamento do projeto e do dimensionamento final empregando método dos elementos finitos para determinar pontos de sobre tensão na geometria inicialmente proposta de modo a permitir as correções necessárias antes da fabricação final.

Uma vez determinadas e validadas as condições geométricas e estruturais dos acessórios, os mesmos foram soldados às plataformas através do processo de soldagem GTAW (Gas Tungsten Arc Welding), ou soldagem TIG (Tungsten Inert Gas), por arco pulsado. Nesta operação empregou-se o consumível AWS ER 4043 [8], cuja composição química e propriedades de tração estão mostradas na Tabela 1.

Tabela 1. Composições químicas e características mecânicas dos materiais empregados [5 e 8].

\begin{tabular}{|c|c|c|c|}
\hline Item & Descrição & $\begin{array}{c}\text { Composição Química } \\
\text { (relevantes*) }\end{array}$ & $\begin{array}{l}\text { Propriedades obtidas por } \\
\text { ensaio de tração (relevantes*) }\end{array}$ \\
\hline Plataformas & AA3105-H14 & $\begin{array}{c}\text { 95,9\%Almín. / 0,20 a } \\
\text { 0,80\%Mg / 0,30 a 0,80\%Mn }\end{array}$ & 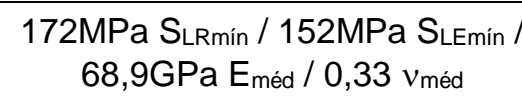 \\
\hline $\begin{array}{l}\text { Componentes } \\
\text { (cond. inicial) }\end{array}$ & AA1060-O & 99,60\%Almín. & $\begin{array}{c}55 \text { a 95MPa SLR / 17MPa SLEmín } \\
\text { 68,9GPa E Eméd / 0,33 } v_{\text {méd }}\end{array}$ \\
\hline $\begin{array}{l}\text { Componentes } \\
\text { (cond. final) }\end{array}$ & AA1050-H16 & 99,50\%Almín. & $\begin{array}{c}\text { 131MPa SLR / 124MPa SLEmín / } \\
69,0 \mathrm{GPa} E_{\text {méd }} / 0,33 v_{\text {méd }}\end{array}$ \\
\hline Consumível & $\begin{array}{l}\text { AWS A5.10 } \\
\text { ER } 4043[8]\end{array}$ & $\begin{array}{c}92,3 \text { a } 95,5 \% \mathrm{Al} / \\
\quad 4.5 \text { a } 6.0 \% \mathrm{Si}\end{array}$ & $\begin{array}{c}144 \text { a 227MPa } S_{L R} / 138 \mathrm{MPa} \\
\mathrm{S}_{\mathrm{LEmin}} / 68,9 \mathrm{GPa} \mathrm{E}_{\text {méd }} / 0.33 v_{\text {méd }}\end{array}$ \\
\hline
\end{tabular}

\section{RESULTADOS E DISCUSSÃO}

A posição de trabalho dos acessórios está melhor ilustrada na Figura 3. Nesta figura é possível perceber que o elemento, fixado na parte inferior das plataformas, 
encaixa-se perfeitamente às vigas "U" que compõe as 'terças' da cobertura do telhado, provendo uma fixação segura e simples às plataformas. A geometria dos componentes de fixação foi estabelecida de forma a impactar ao mínimo o possível na massa total do componente e fornecer, ao mesmo tempo, uma fixação justa nos elementos estruturais do telhado, conforme ilustrado na Figura 3.

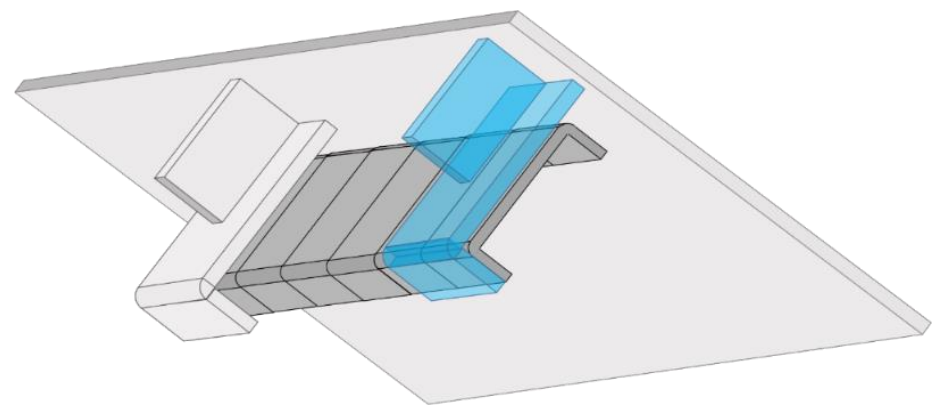

Figura 3. Aspecto de dois elementos de fixação e sua posição relativa ao elemento estrutural do telhado ou 'terça' (em destaque cinza mais escuro).

A Figura 4 ilustra as principais dimensões de um elemento de fixação da plataforma, a ser empregado conforme ilustrado na Figura 3. Nessa Figura é possível perceber os detalhes deste acessório, que é essencialmente compostos de três partes:

1. um elemento de reforço (com dimensões $4,7 \times 100 \mathrm{~mm}$ );

2. um elemento para impedir o deslocamento vertical das plataformas (com dimensões $4,7 \times 50 \mathrm{~mm}$ ) e;

3. um elemento de apoio e transferência de carga das vigas do telhado ('terças') à plataforma (com dimensões $4,7 \times 100 \mathrm{~mm}$ ).

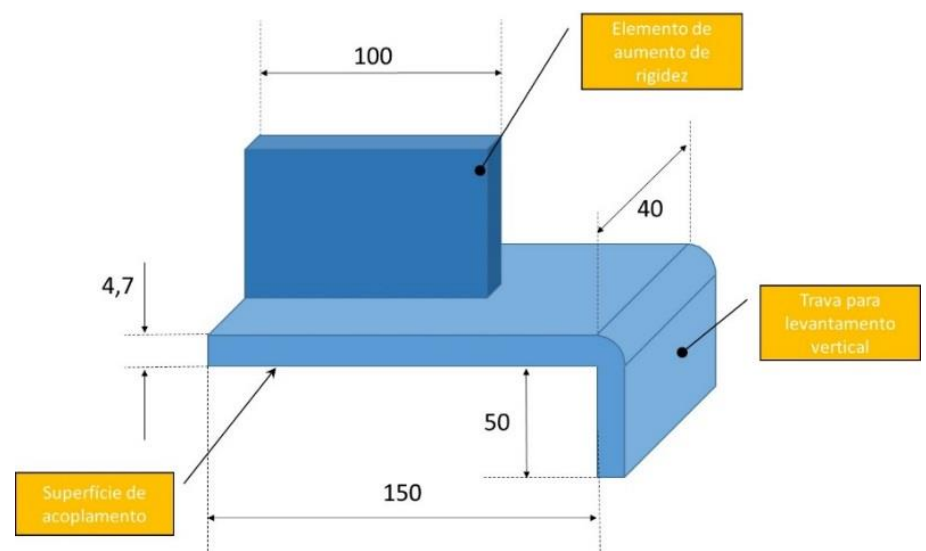

Figura 4. Aspecto inicial e dimensões de um dos elementos de fixação das plataformas.

\subsection{Cálculo Estrutural Analítico}

Para os cálculos adotou-se, por conservadorismo, que o metal de constituição dos elementos de fixação apresenta um baixo nível de resistência mecânica, conforme descrito na Tabela 1. Neste caso, adotou-se um valor de limite de escoamento (SLE) de apenas $17 \mathrm{MPa}$ para o material dos elementos de fixação das plataformas. Esta propriedade é o valor esperado [5] para o alumínio comercialmente puro, padrão AA 1060, na condição de fornecimento recozido (AA 1060-O). 
Considerando que o elemento estrutural está fixo à plataforma por engastamento, oriundo de sua soldagem a esta, então a carga total pode ser descrita de forma distribuída em todo o seu comprimento, conforme ilustrado na Figura 5. Mais uma vez, por questões de segurança e conservadorismo nos cálculos, considerou-se que toda a carga deve ser suportada apenas na região mais rígida do elemento, com $100 \mathrm{~mm}$ de comprimento, conforme apresentado na Figura 5. Existe uma parcela do esforço que é distribuída na região sem reforço, mas esta será desprezada.

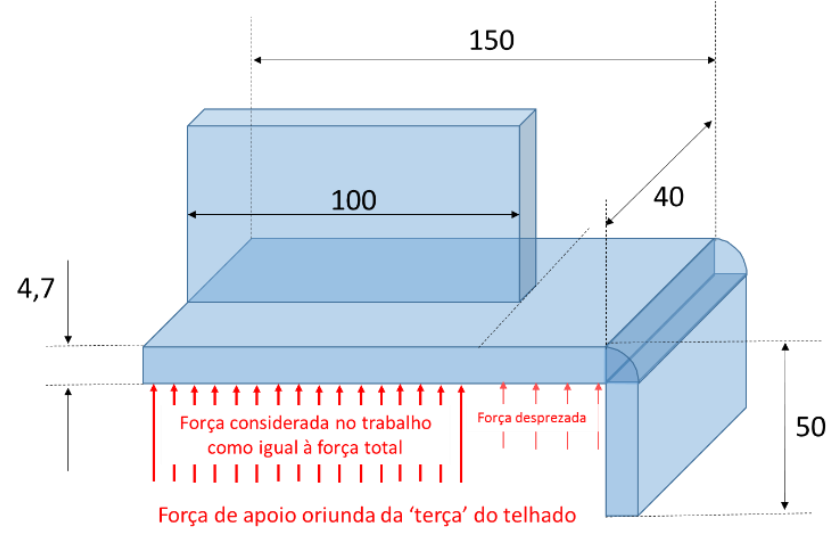

Figura 5. llustração da distribuição da carga de apoio (reação) entre o componente de fixação e a viga de apoio no telhado ('terça').

Para determinar a força que cada elemento de fixação da plataforma deverá suportar, considerou-se que:

1. a massa de cada plataforma como sendo igual à $15 \mathrm{~kg}$;

2. a massa de um usuário da plataforma igual à $100 \mathrm{~kg}$ (considerando os equipamentos de segurança);

3. o ângulo do telhado e consequentemente da inclinação de trabalho das plataformas igual à 50 graus;

4. a existência de dois elementos de fixação exatamente iguais e homogeneamente espaçados.

Desta forma, considerando a massa total (MT) de 115kgf, obtêm-se:

$$
\text { Força total }\left(\mathrm{F}_{\mathrm{T}}\right)=\mathrm{M}_{\mathrm{T}} \times \cos \left(90^{\circ}-50^{\circ}\right) \times 9,806=431,9 \mathrm{~N}
$$

A Figura 6 ilustra a carga atuante total, a força em cada elemento e a força distribuída ao longo da parte rígida do elemento (vide Figura 5). 


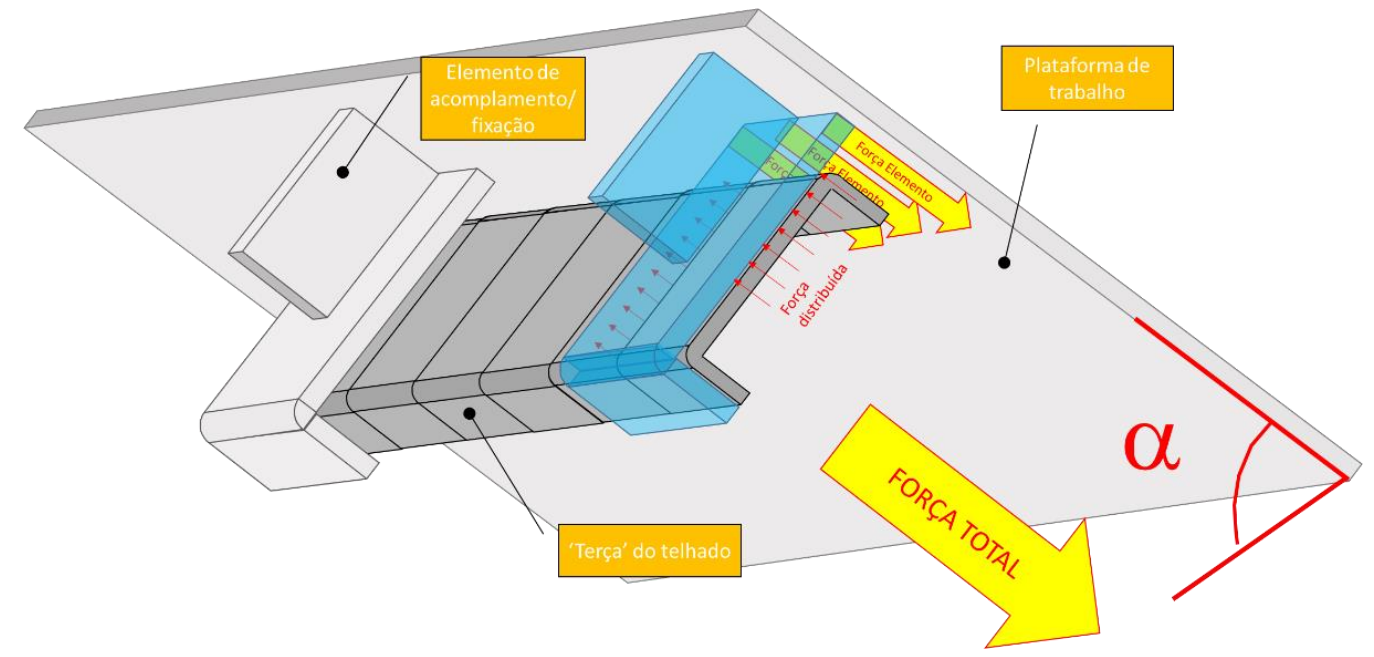

Figura 6. llustração da atuação dos elementos de fixação das plataformas e a distribuição da carga entre o componente de fixação e a viga de apoio no telhado ('terça').

O momento fletor $\left(\mathrm{Mb}_{\mathrm{b}}\right)$ em cada elemento pode ser calculado, considerando carga distribuída (Figura 5) ao longo do comprimento do elemento na parte enrijecida $(100 \mathrm{~mm})$, conforme a equação, disponível na literatura [6]:

$$
\text { Momento Fletor }\left(\mathrm{Mb}_{\mathrm{b}}\right)=\left(\mathrm{F}_{\mathrm{T}} / 2\right) \times \mathrm{I}=(431,9 / 2) \times 100=21.596,5 \mathrm{~N} \cdot \mathrm{mm}
$$

A tensão de flexão que surge na base do elemento, considerando-o engastado à base da plataforma (pela soldagem TIG), pode ser calculada conforme a equação, também disponível na literatura [6]:

Tensão para flexão $(\sigma b)=\mathrm{Mb}_{\mathrm{b}} \times \mathrm{e} / \mathrm{I}_{\mathrm{T}}=21.596,5 \times 13,5 / 72.191,5=4,04 \mathrm{~N} / \mathrm{mm}^{2}$

Onde: e - distância do eixo neutro à base de apoio; IT - momento de inércia da seção reta e $1 \mathrm{~N} / \mathrm{mm} 2=1 \mathrm{MPa}$.

O cálculo do eixo neutro e do momento de inércia do elemento foram feitos em separado. Considerando que a maior tensão aplicável é limitada pelo limite de escoamento (SLE) do material, considerado conservadoramente igual à $17 \mathrm{MPa}$ (Tabela 1), pode-se determinar um fator de segurança mínimo para o elemento de fixação oferecido por:

$$
\text { Fator de segurança }\left(F_{S}\right)=S_{L E} / \sigma_{b}=17 / 4=4,20
$$

Considerando que os elementos e a plataforma serão constituídos por ligas de alumínio com graus de resistência (SLE) ao menos 6 vezes maiores (SLE₹100MPa) [5], é possível considerar que os componentes de fixação das plataformas estão dimensionados com um maior nível de segurança. Esta questão é importante, inclusive para prever eventuais alterações devido a tratamentos térmicos imprevistos, oriundos, por exemplo, de respingos de soldagem realizados no campo. Conforme requisitado pela NR-18 [2], torna-se necessário que o dimensionamento dos componentes seja realizado por profissional devidamente qualificado. Por isso, todos os cálculos apresentados devem estar acompanhados de uma Anotação de Responsabilidade Técnica (ART), emitida pelo Conselho Regional de Engenharia e Agronomia (CREA) do estado onde esta produto será empregado ou fabricado. 


\subsection{Ensaios Mecânicos nas Chapas Empregadas no Produto}

A Figura 7 ilustra o equipamento de testes e algumas curvas de tração obtidas. Foram empregadas duas velocidades de ensaio, de forma a ser obtida a sensibilidade à taxa de deformação do material à temperatura ambiente $(\mathrm{m})$. Neste caso, o valor encontrado foi $\mathrm{m}=0,0046$ e poderá ser empregado caso seja necessário analisar, no futuro, efeitos de carregamentos rápidos nos componentes. Nos ensaios realizados, obteve-se para este material: SLEMéd=129MPa e SLRMéd=160MPa. Estes resultados são compatíveis para o material AA 1050-H16, disponível no mercado nacional [9].
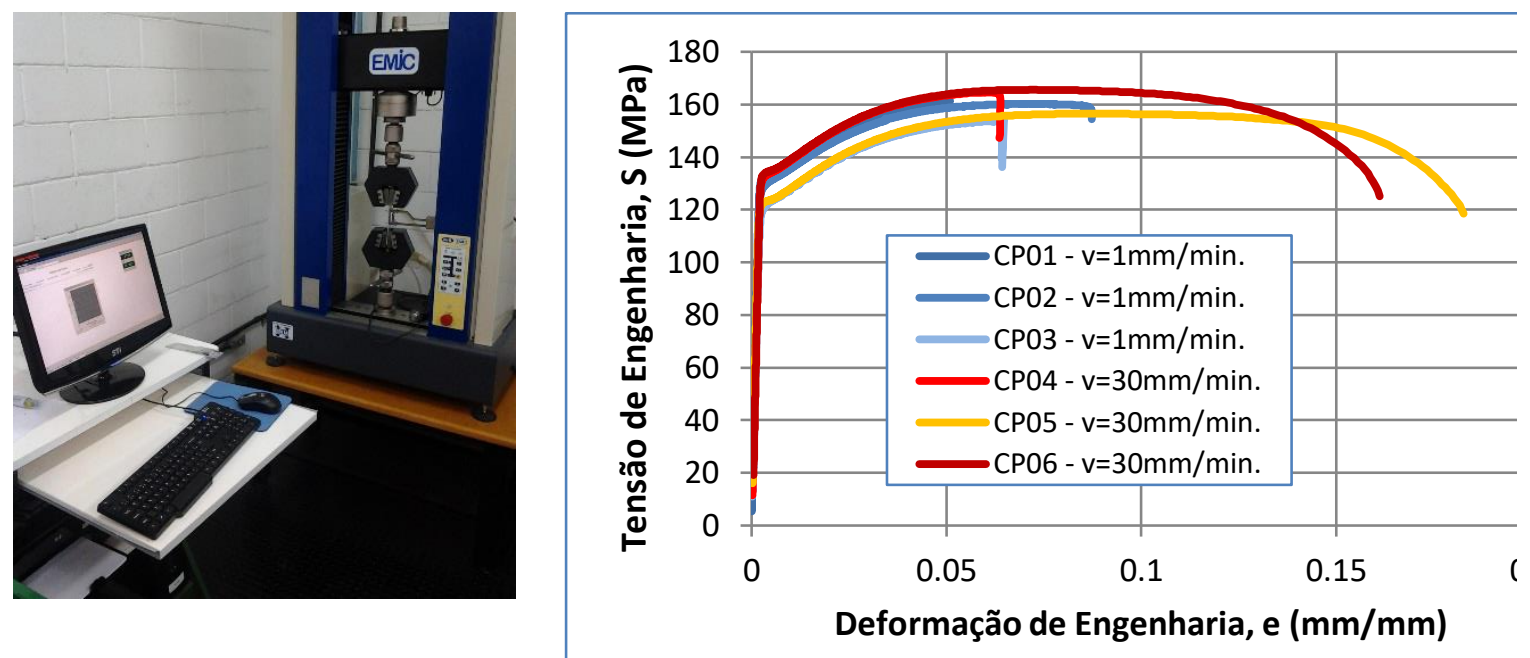

Figura 7. À esquerda: fotografia do equipamento de ensaios de tração sendo empregado para caracterizar o material empregado na fabricação dos acessórios. À direita: algumas das curvas de tração obtidas após os ensaios de tração. 


\subsection{Cálculo Estrutural por Elementos Finitos (FEA)}

Para o dimensionamento detalhado dos componentes efetuou-se uma análise estática pelo método de elementos finitos. Nesta determinação empregaram-se elementos triangulares bidimensionais, possuindo em cada nó dois graus de liberdade em translação. As condições de contorno foram definidas de forma que represente realisticamente as restrições do componente, aplicando assim uma força normal a face de contato do componente com a terça do telhado de $431,9 \mathrm{~N} \mathrm{e}$ fixando a face de contado com a plataforma de trabalho. A Tabela 2 apresenta um resumo das condições consideradas. No caso das propriedades mecânicas, considerou-se os valores mínimos obtidos nos ensaios de tração (item 3.2).

Tabela 2. Dados básicos empregados na análise por elementos finitos (FEA).

Referência do Modelo

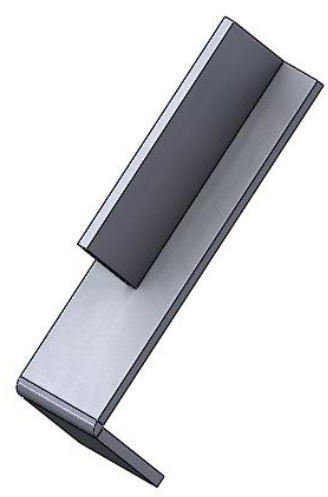

\section{Características}

\section{Nome: $\quad A A 1050 \mathrm{H} 16$}

Tipo de modelo: Isotrópico linear elástico

Critério de falha predeterminado: Tensão de von Mises máxima

Limite de escoamento: $124 \mathrm{~N} / \mathrm{mm}^{2}$

Resistência à tração: $131 \mathrm{~N} / \mathrm{mm}^{2}$

Resistência à compressão: $131 \mathrm{~N} / \mathrm{mm}^{2}$

Módulo elástico: $69000 \mathrm{~N} / \mathrm{mm}^{2}$

Coeficiente de Poisson: 0.33

Massa específica: $2710 \mathrm{~g} / \mathrm{cm}^{3}$

Módulo de cisalhamento: $26000 \mathrm{~N} / \mathrm{mm}^{2}$

A Tabela 3 apresenta os principais resultados numéricos do modelamento e as Figuras 7.a a 7.d apresentam os resultados gráficos. A máxima tensão obtida no modelamento foi de 55,9MPa, conforme ilustrado no gráfico das tensões de Von Mises, apresentado na Figura 7.d.

Tabela 3. Resultados numéricos básicos obtidos pela análise por elementos finitos (FEA).

\section{Forças de reação}

\begin{tabular}{|c|c|c|c|c|c|}
\hline $\begin{array}{l}\text { Conjunto de } \\
\text { Seleção }\end{array}$ & Unidades & Soma $X$ & Soma Y & Soma Z & Resultante \\
\hline Modelo inteiro & $\mathrm{N}$ & 277.624 & -330.863 & 0.0 & 431.909 \\
\hline \multicolumn{6}{|c|}{ Momentos de reação } \\
\hline $\begin{array}{l}\text { Conjunto de } \\
\text { Seleção }\end{array}$ & Unidades & Soma X & Soma Y & Soma Z & Resultante \\
\hline Modelo inteiro & $\mathrm{N} \cdot \mathrm{m}$ & 0.0 & 0.0 & 0.906089 & 0.906095 \\
\hline \multicolumn{6}{|c|}{ Detalhes da malha } \\
\hline \multicolumn{2}{|c|}{$\begin{array}{r}\text { Pontos Jacobianos } \\
\text { Tamanho do Elemento }\end{array}$} & $\begin{array}{l}4 \text { pontos } \\
2.36109 \mathrm{~mm}\end{array}$ & & $\begin{array}{r}\text { Tolerância } \\
\text { Total de nós } \\
\text { de elementos }\end{array}$ & $\begin{array}{l}0.118055 \mathrm{~mm} \\
14958 \\
7300\end{array}$ \\
\hline
\end{tabular}

Em termos de análise estática, através do método dos elementos finitos, o Fator de Segurança mínimo obtido foi de 2,25; portanto menor do que o fator de 4,2 obtido analiticamente (Eq. 4). Isso ocorre devido ao ponto de concentração de tensões que 
é criado na região final do enrijecedor do componente a $100 \mathrm{~mm}$ da base soldada do componente. Este resultado surtiu uma ação durante a operação de soldagem: depositar um cordão de solda na região identificada de concentração de tensão de modo a diminuir este efeito.

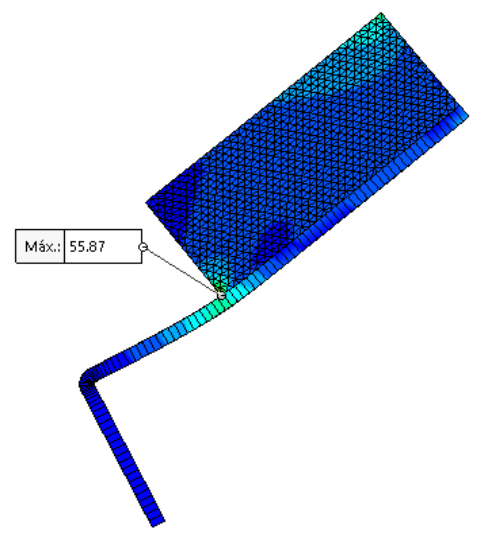

(a)

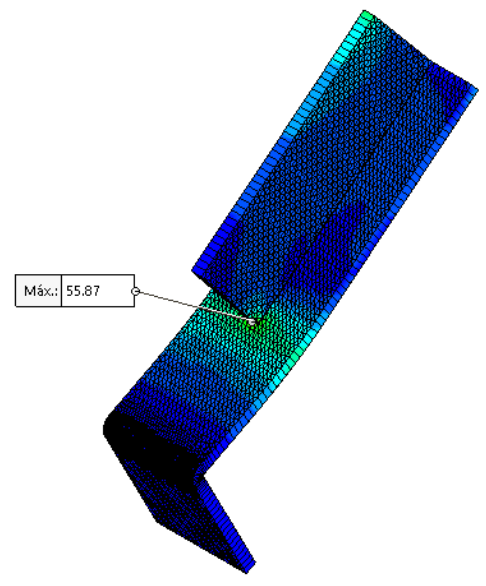

(b)

Tensão de Von Mises no componente.

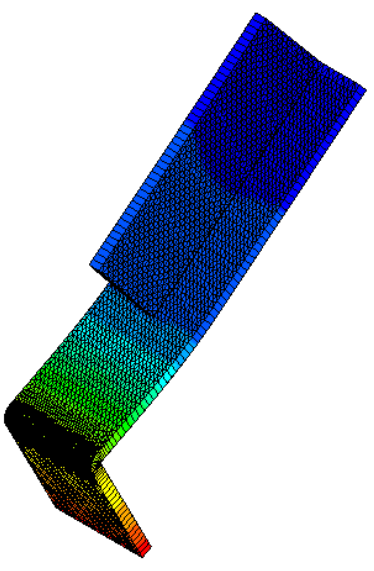

(c)

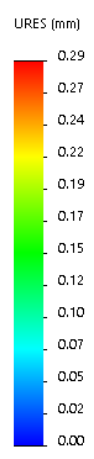

Deslocamentos obtidos

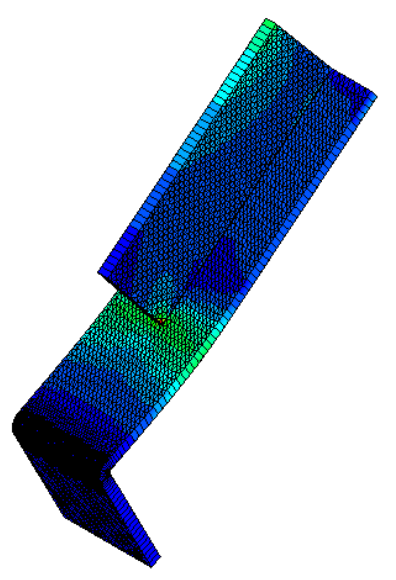

(d)

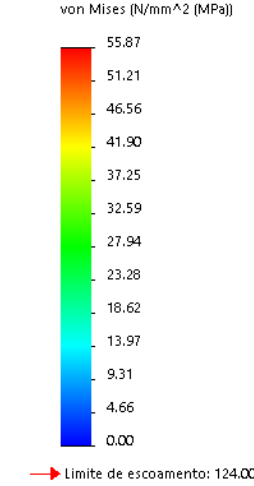

Deformações obtidas.

Figura 7. Resultados do modelamento obtidos através da análise por elementos finitos (FEA) dos

\subsection{Soldagem} componentes acessórios constituídos de AA 1050-H16.

Os componentes, uma vez dimensionados, foram fabricados através do dobramento de uma chapa de liga de alumínio AA $1050-\mathrm{H} 16$ de $200 \times 40 \times 4,7 \mathrm{~mm}$ e sua soldagem a outra chapa plana do mesmo material com dimensões $100 \times 40 \times 4,7 \mathrm{~mm}$ de modo a obter a geometria ilustrada na Figura 4. Estas duas peças foram soldadas através do processo GTAW (ou TIG) empregando-se uma fonte máquina de solda Miller Dynasty ${ }^{\circledR} 210$ Series, empregando uma corrente entre $76 \mathrm{~A}$, voltagem de 19 a 21V e Corrente Alternada (CA) com uma frequência de $100 \mathrm{~Hz}$. Como consumível, empregou-se o AWS A5.10 ER 4043 [8] e para limpeza das superfícies antes da solda empregou-se acetona industrial $\left(\mathrm{C}_{3} \mathrm{H}_{6} \mathrm{O}\right)$.

A Figura 8 ilustra as operações de soldagem dos componentes. Uma vez terminadas, estas soldas foram inspecionadas para averiguar a qualidade $e$ homogeneidade dos cordões depositados. O produto final, cujo aspecto está 
ilustrado na Figura 9. já pode ser empregado em campo, sem maiores necessidades de acabamento.

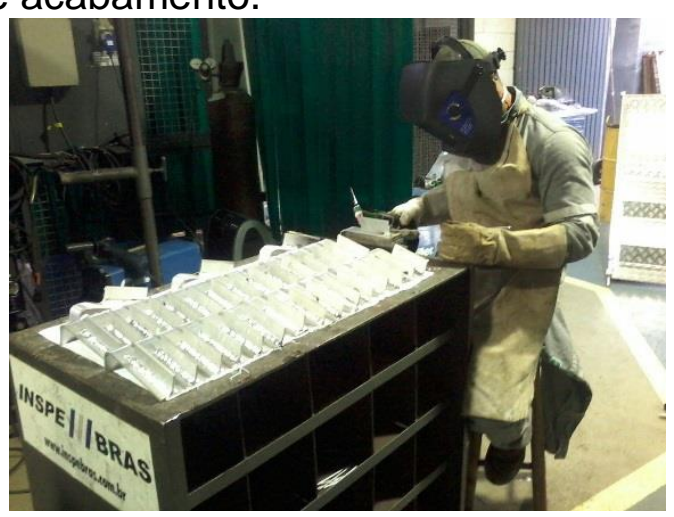

Montagem dos componentes

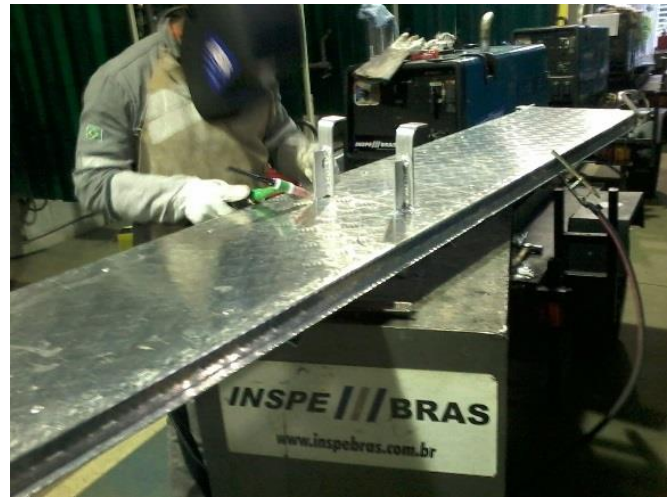

Fixação dos componentes às plataformas

Figura 8. Exemplificação das operações de soldagem GTAW empregadas para finalizar o produto.

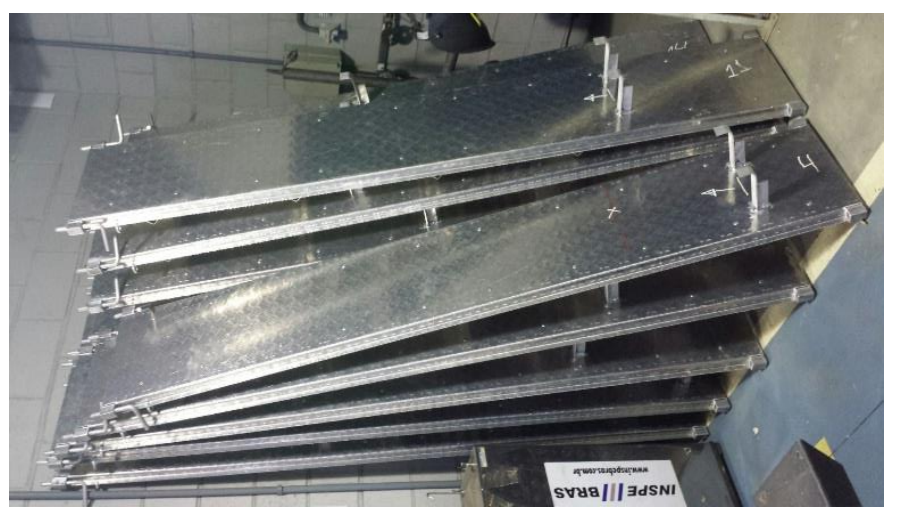

Figura 9. Exemplificação das operações de soldagem GTAW empregadas para finalizar o produto.

\section{CONCLUSÃO}

Este trabalho descreveu as operações de análise, caracterização, projeto e adequação de dispositivos de segurança em plataformas para trabalho em altura constituídas em ligas de alumínio AA 3105-H14. Estes componentes puderam ser modificados a partir de cálculo estrutura e pela análise por elementos finitos (FEA). Os equipamentos obtidos, atendendo às condições de segurança solicitadas pela NR-18, foram disponibilizados para emprego imediato. Graças às características do alumínio, as plataformas mantiveram o seu peso original (15kg por unidade de $2,5 \mathrm{~m}$ ) e não precisaram receber outras formas de acabamento para seu uso imediato.

\section{REFERÊNCIAS}


COMPANHIA HIDRO-ELÉTRICA DO SÃO FRANCISCO (CHESF). Orientações básicas para trabalhos em telhados. Disponível em:

http://www5.chesf.gov.br/Anexos/FOLDER\%20Telhados.pdf. <Acesso em 5 Out. 2015>.

2 Brasil. Ministério do Trabalho e Emprego. Norma regulamentadora no 18 (Condições e meio ambiente de trabalho na indústria da construção). Disponível em:

http://portal.mte.gov.br/index.php/seguranca-e-saude-no-trabalho/2015-09-14-19-1840/2015-09-14-19-23-50/2015-09-29-20-46-56. <Acesso em 5 Out. 2015>.

3 DULLY. Catálogo de Produtos on-line: Passarela de Alumínio com Degrau DLPD001. Disponível em: http://www.dully.com.br/produtos/trava-quedas/passarelas-dealuminio.html. <Acesso em 5 Out. 2015>.

4 GULLIN. Trabalho em telhados e coberturas - sistema de movimentação nos telhados e coberturas. Disponível em: http://www.gulin.com.br/produtosdetalhe.asp? IDMenu=22\&IDCat=41\&IDProd=194. <Acesso em 5 Out. 2015>.

5 MATWEB: Material Property Data. 2015. Disponível em: http://www.matweb.com/search/PropertySearch.aspx. < Acesso em 5 Out. 2015>.

6 BEER, Ferdinand P.; DEWOLF, John T.; JOHNSTON, E. Russell, Jr. Resistência dos Materiais - 4" Ed. Mc Graw Hill, 2006.

7 ABNT NBR ISO 6892-1:2013. Materiais metálicos - Ensaio de Tração. Parte 1: Método de ensaio à temperatura ambientes, ASSOCIAÇÃO BRASILEIRA DE NORMAS TÉCNICAS, 2013.

8 AWS A5.10/A5.10M:2012. Welding Consumables-Wire Electrodes, Wires and Rods for Welding of Aluminum and Aluminum-Alloys-Classification (Approved as American National Standard), AMERICAN WELDING SOCIETY, 2012.

9 BOLETIM TÉCNICO LAMINADOS - CHAPAS. ALCOA, Maio, 2011. Disponível em: https://www.alcoa.com/brasil/pt/resources/pdf/download/chapas_e_folhas/chapas.pdf. < Acesso em 21 Out. 2015>. 